\title{
Physiological responses of wheelchair athletes at percentages of top speed
}

Division of Sport, Health and Exercise, Staffordshire University, Stoke on Trent, Staffordshire, United Kingdom I G Campbell

Department of Physical Education, Sports Science and Recreation Management, Loughborough University of Technology, Loughborough, United Kingdom C Williams

H K A Lakomy

Correspondence to: Dr Ian G Campbell, Division of Sport, Health and Exercise, Staffordshire University, Leek Road, Stoke on Trent, Staffordshire ST4 2DF.

Accepted for publication 9 July 1996

Ian G Campbell, Clyde Williams, Henryk K A Lakomy

\begin{abstract}
Objective-Wheelchair athletes often select a percentage of their top speed (\%TS) to determine training intensity. The aim of the study was to determine whether choosing a \%TS corresponds to the physiological concept of relative exercise intensity (\% peak oxygen uptake: $\% \mathrm{VO}_{2}$ peak) and to examine selected physiological and metabolic responses of a group of wheelchair athletes to 60 minutes' exercise at $80 \%$ TS.
\end{abstract}

Methods-12 male wheelchair athletes (10 paraplegics and two tetraplegics) performed a series of tests on a motorised treadmill adapted for wheelchairs. The tests, which were undertaken on separate occasions, included the determination of $\dot{\mathrm{VO}}_{2}$ peak, the determination of oxygen cost at a range of submaximal wheelchair propulsion speeds, and a $60 \mathrm{~min}$ exercise test at $80 \%$ TS.

Results-Wheelchair propulsion speeds equivalent to $60 \%, 70 \%, 80 \%$, and $90 \%$ of each subject's TS were found to equate to 48.3(SD13.8)\%, 60.0(11.1)\%, 70.6(9.8)\%, and $82.7(9.6) \%$ of $\dot{V}_{2}$ peak, with a wide variation in the relative exercise intensities evident at each \%TS. During the $1 \mathrm{~h}$ exercise test at $80 \%$ TS the physiological and metabolic responses measured were indicative of steady state exercise, with no signs of fatigue evident.

Conclusions-The results of this study suggest that selecting a \%TS is not an appropriate way of selecting a common relative exercise intensity. There may also be a need for the current training practises of some wheelchair road racers to be modified.

(Br F Sports Med 1997;31:36-40)

Keywords: wheelchair athletes; endurance exercise; training methods.

The term "top speed" is part of the training vocabulary of all wheelchair road racers and is entirely empirically based. It is derived from competition racing and refers to the highest speed that a wheelchair athlete can achieve for a particular event. Selecting a percentage of top speed (\%TS) is a method which is regularly used by wheelchair road racers and coaches involved in the sport to determine training intensity. If selecting a \%TS corresponds to a common relative exercise intensity $\left(\% \dot{\mathrm{VO}}_{2}\right.$ peak) this method would have scientific credibility to the exercise physiologist as it would have physiological validity. As yet this has not been established. Furthermore, the relative exercise intensities represented at different percentages of top speed have not been reported.

As well as using \%TS to determine training intensity, wheelchair athletes also commonly describe the exercise intensity at which they are working during an endurance event in terms of the percentage top speed sustained during the race. A speed frequently selected by wheelchair road racers for endurance training and racing is $80 \%$ TS; however, the physiological and metabolic responses to endurance exercise at a fixed percentage of top speed have not been reported. It is also interesting to note that wheelchair athletes have been shown to use around $80 \% \quad \mathrm{~V}_{2}$ peak during endurance races. ${ }^{1}$ As such, it is of interest to know whether $80 \%$ TS corresponds to $80 \% \quad \mathrm{VO}_{2}$ peak. Furthermore, if $80 \%$ TS does equate to $80 \%$ $\mathrm{VO}_{2}$ peak there is some cause for concern for individuals taking up the sport, as this intensity would be too high as an initial training intensity.

The purpose of this present study was therefore to determine whether choosing a \%TS corresponds to a common relative exercise intensity [\% peak oxygen uptake $\left(\mathrm{V}_{2}\right.$ peak)] and to examine selected physiological and metabolic responses of a group of wheelchair athletes to 60 minutes' exercise at $80 \%$ TS.

\section{Methods}

Twelve male wheelchair athletes volunteered to participate in this study which required the subjects to complete a series of preliminary tests and one hour of exercise at $80 \%$ of their top speed (80\% TS). All subjects trained regularly for, and competed regularly in, endurance races. Furthermore all the athletes were experienced racers and had been competing for more than five years [mean (SD): 9.4 (2.6) years]. The group did, however, vary in racing standard from athletes who competed at an international level $(n=6)$ to those who competed at a more recreational level $(n=6)$. The athletes also differed in terms of their lesion levels. In this respect there were 10 paraplegics in the group (lesion levels: T2-L2) and two tetraplegics (lesion levels: C7; C7 incomplete). Eight of the subjects had acquired their spinal cord injury as a result of trauma, while for the other four subjects the neurological deficit was a result of spina bifida.

All tests were performed on a motorised treadmill which had been adapted for wheelchairs (fig 1, top). This system had been updated from that originally developed at this 

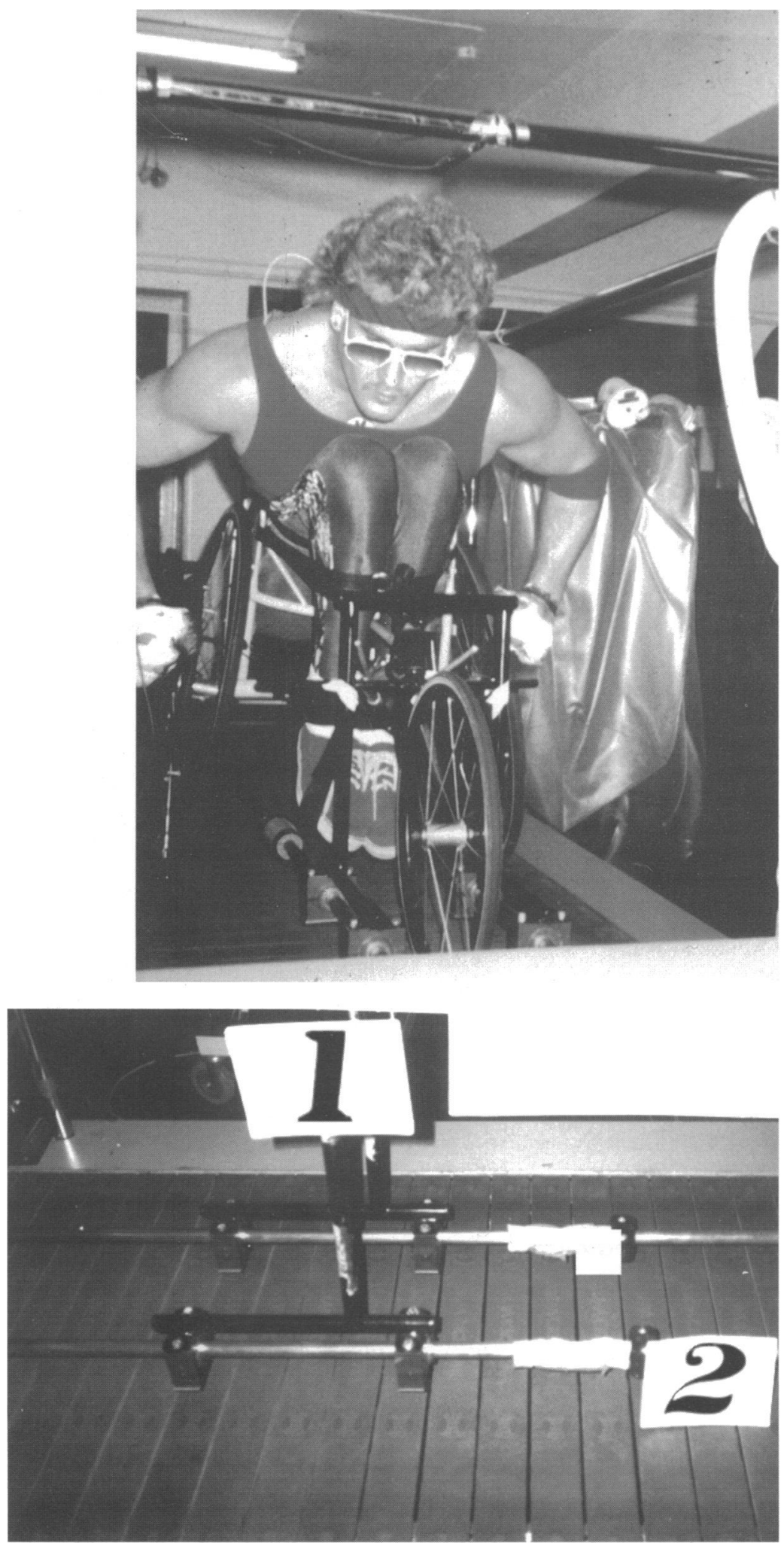

Figure 1 Top: the wheelchair treadmill system; bottom: the slider mechanism.

laboratory ${ }^{2}$ in order to accommodate the latest three wheel racing chairs. The system differs from the original in that it has a central channel which allows the middle front wheel to run freely on the treadmill belt. The treadmill adaptation allowed the subject's own "racing" wheelchair to be attached to the slider mechanism at position 1 (fig 1 , bottom), which allowed freedom of movement both forwards and backwards but restricted sideways move- ment. A safety backstop mounted at position 2 (fig 1, bottom) prevented the wheelchair from travelling backwards off the treadmill belt should the athlete stop pushing. Before any testing all subjects were fully familiarised with wheelchair treadmill exercise and the methods used in the laboratory for monitoring heart rate, the collection of expired air, and obtaining capillary blood samples. ${ }^{3}$

The peak oxygen uptake $\left(\dot{\mathrm{VO}}_{2}\right.$ peak) of each individual was determined using a continuous incremental speed protocol. ${ }^{2}$ Before the test the subjects followed their usual warm up procedures which were all submaximal in nature. During the test the treadmill remained horizontal and the speed of the treadmill was increased at three minute intervals. The starting treadmill speed for the test was selected on the basis of performance during previous visits to the laboratory. Expired air was collected for 60 seconds from $1 \mathrm{~min} 45 \mathrm{~s}$ to $2 \mathrm{~min} 45 \mathrm{~s}$ of each exercise period. The test protocol was open ended and continued until the subjects indicated that they could only continue the test for a further minute, when a final expired air collection was obtained. For the purposes of the present study the speed achieved during the final minute of $\dot{\mathrm{V}} \mathrm{O}_{2}$ peak test was defined as the top speed (TS) for each athlete.

On a separate occasion the oxygen cost $\left(\dot{\mathrm{VO}}_{2}\right.$, litres $\left.\mathrm{min}^{-1}\right)$ for each subject was determined at four submaximal wheelchair propulsion speeds $\left(\mathrm{m} \mathrm{s}^{-1}\right)$. The submaximal speeds selected were equivalent to $60 \%, 70 \%$, $80 \%$, and $90 \%$ of each athlete's top speed achieved during the $\dot{\mathrm{VO}}_{2}$ peak test. This test was a continuous 16 minute test and required subjects to exercise for four minutes at each speed. Expired air samples were collected during the last minute of each four minute period.

The final test that each subject performed was of one hour's duration at a speed equivalent to $80 \%$ TS. Subjects arrived at the laboratory in a rested state and at least four hours after their last meal. Before the test, duplicate $20 \mu \mathrm{l}$ capillary blood samples were taken from an earlobe. Four chest electrodes were then attached to the athlete to monitor heart rate. After each athlete had completed their own warm up on the treadmill they began pushing at a constant pace $(80 \%$ TS ) for one hour. Expired air samples were collected every 15 minutes. Following each of these collections the subject stopped pushing and duplicate samples of capillary blood $(20 \mu \mathrm{l})$ were taken from the earlobe. As soon as the sample had been obtained, which took approximately 20 seconds, the athlete began pushing again. Heart rate was monitored throughout the test, with samples recorded by the computer every 15 seconds. Natural ventilation and electric fans (Expelair, T-16) provided cool air during the test, and laboratory temperature was in the range $18-20^{\circ} \mathrm{C}$.

The blood samples were deproteinised in $0.38 \mathrm{M}$ perchloric acid, frozen, and later analysed for the concentrations of glucose and lactate by the methods described by Maughan. ${ }^{4}$ 
Table 1 Physiological characteristics of the tetraplegics, the paraplegic group, and the whole group of wheelchair athletes, mean (SD)

\begin{tabular}{|c|c|c|c|c|c|}
\hline Lesion level & $\begin{array}{l}\text { Age } \\
\text { (years) }\end{array}$ & $\begin{array}{l}\dot{V} \mathrm{O}_{2} \text { peak } \\
\left(\mathrm{min}^{-1}\right)\end{array}$ & $\begin{array}{l}V E \text { peak } \\
\left(\text { min }^{-1}\right)\end{array}$ & $\begin{array}{l}\text { HR peak } \\
\text { (beats } \text { min }^{-1} \text { ) }\end{array}$ & $R$ \\
\hline \multicolumn{6}{|l|}{ Tetraplegics $(n=2)$} \\
\hline $\mathrm{C} 7$ & 39 & 1.06 & 29.1 & 113 & 0.94 \\
\hline C7 (incomplete) & 28 & 1.39 & 60.1 & 164 & 1.02 \\
\hline \multicolumn{6}{|l|}{ Paraplegics $(n=10)$} \\
\hline \multicolumn{6}{|l|}{ Whole group } \\
\hline C7-L2 & $28(7)$ & $1.80(0.55)$ & $67.8(23.2)$ & $186(26)$ & $1.09(0.08)$ \\
\hline Range & $19-39$ & $1.06-3.02$ & $29.5-109.3$ & $113-209$ & $0.94-1.23$ \\
\hline
\end{tabular}

$\dot{\mathrm{VO}}_{2}$, peak oxygen consumption; $\mathrm{VE}$, ventilation; $\mathrm{HR}$, heart rate; $\mathrm{R}$, respiratory exchange ratio.

\section{STATISTICAL ANALYSIS}

The descriptive statistics reported in the text and the tables refer to group means and standard deviations (SD). The results from the one hour endurance test were analysed using a one way analysis of variance (ANOVA) for repeated measures. When differences were revealed using ANOvA, then a Tukey post hoc test was applied in order to identify where the differences were. Values at the 0.05 level were accepted as being statistically significant.

\section{Results}

The physiological characteristics of the two tetraplegic athletes, the paraplegic group, and the whole group of wheelchair athletes in this study are shown in table 1 . The mean (SD) $\dot{\mathrm{VO}}_{2}$ peak value for the group was $1.80(0.55)$ litres $\mathrm{min}^{-1}$ with a range of 1.06 to 3.02 litres $\min ^{-1}$.

The wheelchair propulsion speeds selected for the preliminary submaximal test were equivalent to $60 \%, 70 \%, 80 \%$, and $90 \%$ of each subject's top speed achieved during the $\dot{\mathrm{VO}}_{2}$ peak test. These speeds equated to 48.3(13.8)\%, 60.0(11.1)\%, 70.6(9.8)\%, and $82.7(9.6) \% \mathrm{VO}_{2}$ peak, respectively, in this group of wheelchair athletes. The relation between oxygen cost and submaximal wheelchair propulsion speeds for this group of wheelchair athletes is shown in fig 2 . The relations for two subjects are also shown to illustrate the differences that can exist between subjects (fig 2 ).

During the one hour endurance test at $80 \%$ $\mathrm{TS}, \dot{\mathrm{VO}} \mathrm{O}_{2}$ and ventilation of the group $(\mathrm{n}=12)$ remained stable throughout the test (table 2), while there was a decrease in the respiratory exchange ratio from $0.87(0.05)$, recorded after 15 minutes, to $0.81(0.04)(P<0.01)$ recorded during the last minute of exercise.

Heart rate increased continuously for the first 45 minutes and then plateaued during the

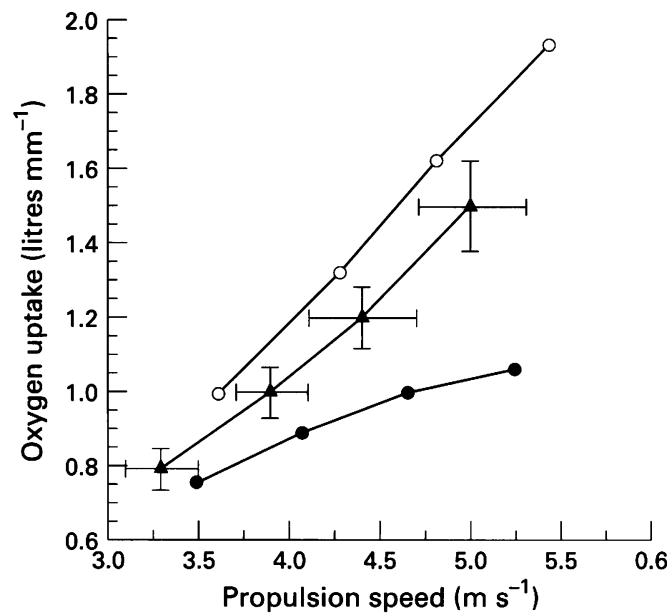

Figure 2 Relation between oxygen uptake (litres min $^{-1}$ ) and wheelchair propulsion speeds $\left(\mathrm{m} \mathrm{s}^{-1}\right)$ equivalent to $60 \%$ $70 \%, 80 \%$, and $90 \%$ top speed for the group $(n=12)$ of wheelchair athletes. Error bars $=S E M$. Filled triangles, the whole group; filled circles, subject $A$; empty circles, subject $B$.

last 15 minutes of exercise (fig 3). The heart rate responses of the two tetraplegic athletes appeared lower than the paraplegic group throughout the test.

Blood lactate concentrations increased $(P<$ 0.01 ) during the first 15 minutes of exercise. After this peak, all subsequent values were lower $(P<0.01)$, with concentrations approaching those recorded at rest by the end of the hour (table 2). The blood glucose concentrations for the group showed no change from resting values during the 60 minute exercise test (table 2). The rate of perceived exertion also showed no change during the exercise period, with a mean value of $13(2)$. The values are given in table 2 .

\section{Discussion}

The main finding of this study was that selecting a percentage of top speed, a method regularly used by wheelchair road racers to determine a training intensity, was not an appropriate way of selecting a common relative exercise intensity ( $\% \dot{\mathrm{VO}}_{2}$ peak). Therefore, from an exercise physiologist's perspective, the top speed method currently employed by these athletes has little scientific credibility as it lacks physiological validity.

Speeds equivalent to $60 \%, 70 \%, 80 \%$, and $90 \%$ of top speed (\%TS) did not correspond to $60 \%, 70 \%, 80 \%$, and $90 \%$ of $\dot{\mathrm{V}} \mathrm{O}_{2}$ peak. These percentages of top speed actually represented, on average, relative exercise intensities of $48 \%$,

Table 2 Physiological and metabolic responses of the group of wheelchair athletes $(n=12)$ during the endurance test at $80 \% \mathrm{TS}$, mean (SD)

\begin{tabular}{|c|c|c|c|c|c|c|}
\hline Time (min) & Rest & 15 & 30 & & 45 & 60 \\
\hline$\overline{\mathrm{V}} \mathrm{O}_{2}\left(1 \mathrm{~min}^{-1}\right)$ & - & $1.13(0.35)$ & 1.10 & $(0.29)$ & $1.13(0.25)$ & $1.09(0.20)$ \\
\hline $\operatorname{VE}\left(1 \mathrm{~min}^{-1}\right)$ & - & $31.8(7.7)$ & 30.0 & (6.5) & $31.6(6.9)$ & $29.8(7.1)$ \\
\hline HR (beats $\min ^{-1}$ ) & (10) & $148 \quad(22)$ & 152 & (25) & $155 \quad(22)$ & $155 \quad(22)$ \\
\hline $\mathbf{R}$ & - & $0.87(0.05)$ & 0.84 & $(0.05)$ & $0.83(0.05)$ & $0.81(0.04)$ \\
\hline BLA $\left(\mathrm{mmol} \mathrm{l}^{-1}\right)$ & $1.0(0.1)$ & $3.0(1.6)$ & 2.4 & (1.4) & $2.1(1.1)$ & $1.8(0.6)$ \\
\hline BGL $\left(\mathrm{mmol} \mathrm{l}^{-1}\right)$ & $4.2(0.3)$ & $4.3(0.4)$ & 4.3 & $(0.3)$ & $4.2(0.3)$ & $4.2(0.3)$ \\
\hline RPE (scale 6-20) & - & (2) & 13 & (2) & (2) & (2) \\
\hline
\end{tabular}

$\dot{\mathrm{V}} \mathrm{O}_{2}$, oxygen consumption; VE, ventilation; $\mathrm{HR}$, heart rate; $\mathrm{R}$, respiratory exchange ratio; BLA, blood lactate; BGL, blood glucose RPE, rate of perceived exertion.

Statistical significance: HR: $P<0.01$, resting heart rate and all other heart rates; $R: P<0.01,15$ and 60 min values; $B L A: P<0.01$, $15 \mathrm{~min}$ and all other values. $P<0.01$, resting BLA and $15 \mathrm{~min}, 30 \mathrm{~min}$, and $45 \mathrm{~min}$ values. 


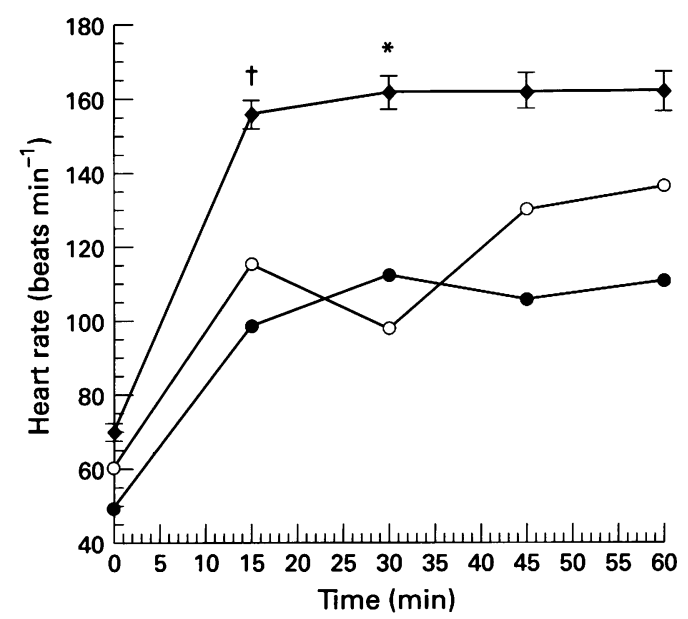

Figure 3 Heart rate (beats $\mathrm{min}^{-1}$ ) during the endurance test at $80 \%$ top speed for the group of paraplegic athletes (n $=10$ ) and the two tetraplegic athletes (C7;C7 incomplete). Filled diamonds, paraplegic group; filled circles, C7; empty circles, $C 7$ incomplete. ${ }^{\star} P<0.05,+P<0.01$ from previous value.

$60 \%, 71 \%$, and $83 \%$ of $\dot{\mathrm{VO}}{ }_{2}$ peak. Furthermore, a wide range of relative exercise intensities was represented at each \%TS, as shown by the large standard deviations. The possible reason for this finding may be the differences between subjects in the way oxygen cost increased with increasing propulsion speed. In this respect some subjects had a greater increase in oxygen uptake for a given speed than others. Such differences in the relation between oxygen cost and propulsion speed have also been reported for running, and suggest that athletes with a higher $\dot{\mathrm{V}} \mathrm{O}_{2}$ max can afford to be less economical at submaximal running speeds. ${ }^{5}$ It is also worth noting that there is likely to be greater variation in oxygen uptake at a given speed for wheelchair racing than for running or cycling due to the differences between wheelchair athletes in terms of factors such as pushing technique, wheelchair hand rim size, and sitting position.

Whatever the reason for the variation in the relative exercise intensities represented at a given \%TS, the result has implications for those designing training schedules for wheelchair users. For example, a coach may recommend that a group of wheelchair athletes should train at $80 \%$ TS in the belief that the group will be working at similar levels of physiological stress. However, our study indicates that this may be inappropriate as athletes would be working at a range of relative exercise intensities. For the majority of athletes this would be lower than is necessary to produce training induced adaptations, but for other wheelchair athletes it may be too excessive.

The mean $\dot{\mathrm{VO}}_{2}$ peak of $1.80(0.55)$ litres $\mathrm{min}^{-1}$ and range of values (1.06 to 3.02 litres $\mathrm{min}^{-1}$ ) found in the present study are consistent with the results of a previous study which employed wheelchair athletes with a similar range of lesion levels (C7-L2). ${ }^{2}$ The finding that the tetraplegic athlete, with a complete lesion at $\mathrm{C} 7$, recorded the lowest $\dot{\mathrm{V}} \mathrm{O}_{2}$ peak is consistent with the results of other studies on tetraplegic athletes. ${ }^{126-9}$ This may be related to the fact that tetraplegics have the greatest loss of sympathetic neural control. The athlete also had the lowest peak heart rate of 113 beats $\mathrm{min}^{-1}$, which is characteristic of this level of spinal cord injury ${ }^{12-9}$ and results from the lack of sympathetic innervation of the heart. ${ }^{10} 11$ This was further substantiated by the very low heart rate of this athlete throughout the one hour test. Interestingly, the tetraplegic athlete with an incomplete cervical lesion had a peak heart rate of 164 beats $\mathrm{min}^{-1}$. This is indicative of loss of some, but not all, the sympathetic nerve supply to the heart. ${ }^{10}$ It should also be mentioned that similar peak heart rate values are sometimes observed in paraplegics with high thoracic lesions because sympathetic innervation of the heart occurs between $\mathrm{T} 1$ and T4. ${ }^{912}$ In the present study the peak heart rate of the paraplegic group was comparable with that achieved by able bodied subjects during uphill treadmill running to exhaustion. ${ }^{13}$

All the wheelchair athletes completed the one hour exercise test at $80 \%$ TS. The physiological and metabolic responses of the group observed during the test were indicative of steady state exercise and consistent with the results of previous wheelchair endurance studies. ${ }^{14-17}$

Pushing economy (oxygen uptake at a given speed) remained relatively stable throughout the hour. This observation is consistent with other wheelchair endurance studies. ${ }^{141517}$ However, the result contrasts with various studies on able bodied subjects exercising in the sitting position $^{18}$ or running ${ }^{19-22}$ which have reported a tendency for oxygen uptake to drift upwards. The ventilation rate also remained stable throughout the endurance test. This is consistent with other wheelchair studies. ${ }^{141517}$ During endurance running it has been reported by some investigators that only when ventilation rate increased did oxygen uptake drift upwards. ${ }^{23}$ As there was no increase in ventilation rate in the present study this may help to explain why oxygen uptake remained stable.

There was a decrease in respiratory exchange ratio ( $R$ value) during the hour, which reflects a shift towards fat metabolism. ${ }^{24}$ This is consistent with studies on both endurance wheelchair exercise $e^{141617}$ and running. ${ }^{2025}$ The finding does not, however, help to explain the stability of pushing economy in the present study. Indeed an increase in oxygen uptake may actually have been expected because of the higher oxygen demand per unit of available ATP required for fat metabolism. ${ }^{23}$ The reason that an increase in oxygen uptake may not be observed despite an increase in fat metabolism may be that an improved mechanical efficiency is achieved through modifications made to propulsion technique during prolonged activity. ${ }^{14}$ This may be achieved, for example, by improving the torque on the hand rim of the wheelchair and thus decreasing the number of stokes per minute. ${ }^{1427}$

Blood lactate concentration peaked after 15 minutes of exercise and then decreased throughout the remainder of the hour. This result is consistent with the results reported in other wheelchair studies. ${ }^{14}$ It is also consistent with endurance running ${ }^{28}$ and arm exercise 
studies, ${ }^{29}$ which have employed relative exercise intensities between $48 \%$ and $70 \%$ of $\mathrm{VO}_{2}$ max, described as moderate to high intensity exercise. $^{28}$ The decrease in blood lactate concentration observed during the hour may indicate increased utilisation of lactate as a substrate. $^{28}$ The finding may also help to explain the stability of oxygen uptake. This is because some studies have suggested that a drift in oxygen uptake will only occur at an exercise intensity where there is an increase in blood lactate concentration. ${ }^{21}$

The gradual increase in heart rate commonly associated with prolonged activity in able bodied subjects ${ }^{1130}$ or upper body exercise $^{29}$ was not observed in this group of wheelchair athletes and is therefore consistent with previous endurance wheelchair studies. ${ }^{14}{ }^{15} \mathrm{In}$ the past, the low relative exercise intensity chosen by these studies has been recognised as one possible reason for this observation. ${ }^{14}{ }^{15}$ This, therefore, may help to explain the result in present study. However, it should be noted that an intensity of around $70 \%$ of $\mathrm{VO}_{2}$ peak has resulted in cardiovascular drift both in lower ${ }^{18}$ and upper body exercise. ${ }^{29}$

In able bodied subjects the cardiovascular drift is related to the peripheral shift of blood volume for temperature regulation. ${ }^{31}$ The drift indicates increased sympathetic activation. ${ }^{11}$ However, as this is lacking to varying degrees in spinal cord injured patients ${ }^{32}$ it may help explain the plateau effect. It has also been suggested that during endurance exercise in individuals with spinal cord injury, stroke volume may remain stable because the reduced active muscle mass will mean that there is less competition between the skin and the muscle mass for the blood volume as thermal load increases. ${ }^{14}$ Consequently heart rate may remain relatively stable.

In summary, in this study we showed that there was a wide range of relative exercise intensities represented at a percentage of top speed. It therefore appears that selecting a $\% \mathrm{TS}$ is not an appropriate way of selecting a common relative exercise intensity for wheelchair athletes. During the endurance test at $80 \%$ TS the physiological and metabolic responses measured were indicative of steady state exercise with no signs of fatigue. Oxygen uptake and ventilation rate remained stable throughout the iest; there was a shift towards fat metabolism; there was no cardiovascular drift; blood lactate concentration peaked after 15 minutes of exercise and then decreased during the rest of the hour; blood glucose concentration remained similar to that recorded at rest; and the perceived rate of exertion remained similar throughout the test.

In conclusion, our results suggest that the method adopted by wheelchair road racers for determining training intensity may not be appropriate and as a result the current training practises of some wheelchair racers may need to be modified.
We are grateful to Bromakin Wheelchairs for providing the wheelchair adaptation for the motorised treadmill.

1 Campbell IG. The influence of level of spinal cord injury on the physiological and metabolic responses of wheelchair athletes to exercise and performance. Loughborough: Loughborough University of Technology, 1992. [PhD thesis.]

2 Lakomy HKA, Campbell IG, Williams C. Treadmil performance and selected physiological characteristics of wheelchair athletes. Br $\mathcal{F}$ Sports Med 1987;21:130-3.

3 Williams C, Nute MLG. Some physiological demands of a half-marathon race on recreational runners. $B r \mathcal{F}$ Sports Med 1983;17:152-61.

4 Maughan RJ. A simple rapid method for the determination of glucose, lactate, pyruvate, alanine, 3-hydroxybutarate and acetoacetate on a single $20 \mu \mathrm{l}$ blood sample. Clin Chim Acta 1982;122:231-40.

5 Mayhew JL. Oxygen cost and energy expenditure of running in trained runners. Br 7 Sports Med 1977;11:116-21.

6 Gass GC, Camp EM. Physiological characteristics of trained Australian paraplegic and tetraplegic subjects. Med Sci Sports Exerc 1979;11:256-9.

7 Gass GC, Watson J, Camp EM, Court HJ, McPherson LM The effects of physical training on high level spinal lesion patients. Scand $\mathcal{f}$ Rehab Med 1980;12:61-5.

8 Eriksson P, Loftstrom L, Ekblom B. Aerobic power during maximal exercise in untrained and well-trained person with quadriplegia and paraplegia. Scand $\mathcal{f}$ Rehab Med 1988;20:141-7.

9 Coutts KD, Rhodes EC, McKenzie DC. Maximal exercise responses of tetraplegics and paraplegics. $\mathcal{f}$ Appl Physiol 1983;55:479-82.

10 Knuttson E, Lewenhaupt-Olsen E. Thorsen M. Physical work capacity condition in paraplegic patients. Paraplegia 1973;11:205-16.

11 Smith EE, Guyton AC, Manning, RD, White RJ. Integrated mechanisms of cardiovascular response and control during exercise in the normal human. Prog Cardiovasc Dis 1976;18:421-43.

12 Johnson RH, Spalding JMK. Autonomic nervous system. Contemporary neurology series, No II. Oxford: Blackwel Scientific Publications, 1974.

13 Ramsbottom R, Williams C, Boobis L, Freeman W. Aerobic fitness and running performance of male and female recreational runners. $\mathcal{f}$ Sports Sci 1987;7:9-20.

14 Gass GC, Camp EM, Davis HA, Eager D, Grout L. The effects of prolonged exercise on spinally injured subjects. Med Sci Sports Exerc 1981;13:277-83.

15 Fitzgerald PI, Sedlock DA, Knowlton RG, Schneider DA Cardiovascular responses of spinal cord injured women to prolonged submaximal wheelchair activity [abstr]. Med Sci prolonged submaximal whe

16 Skrinar GS, Evans WJ, Ornstein LJ, Brown DA. Glycogen utilization in wheelchair dependent athletes. Int $\mathcal{F}$ Sports Med 1982;3:215-9.

17 Gass GC, Camp EM. Effects of prolonged exercise in highly trained traumatic paraplegic men. $\mathcal{F}$ Appl Physiol 1987;63: 1846-52.

18 Ekelund L-G. Circulatory and respiratory adaptation during prolonged exercise of moderate intensity in the sitting position. Acta Physiol Scand 1967;67:327-340.

19 Hagberg JM, Mullin JP, Nagle FJ. Oxygen consumption during constant-load exercise. 7 Appl Physiol (Resp Environ Exerc Physiol) 1978;45:381-4.

20 Hardman AE, Williams C. Exercise metabolism in runners. Br ₹ Sports Med 1983;17:96-101.

21 Casaburi R, Storer TW, Ben-Dov I, Wasserman K. Effect of endurance training on possible determinants of $\mathrm{VO}_{2}$ during heavy exercise. $\mathcal{F}$ Appl Physiol 1987;62:199-207.

22 Camus G, Atchou G, Bruckner JC, Giezendanner D, Di Prampero PE. Slow upward drift of $\mathrm{VO}_{2}$ during constant-

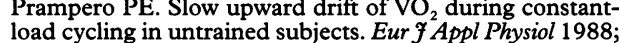
load cycling in
$58: 197-202$.

23 Hardman AE. Human adaptations to endurance training: the influence on the ability to sustain submaximal exercise. Loughborough: Loughborough University of Technology, 1984. [PhD thesis.]

24 Felig P, Wahren J. Fuel homeostasis in exercise. $N$ Engl $f$ Med 1975; 293:1078-84.

25 Costill DL. Metabolic responses during distance run. $f$ App Physiol 1970;28:251-5.

$26 \mathrm{Hartley} \mathrm{LH}$. Central circulatory function during prolonged exercise. Ann NY Acad Sci 1977;301:189-94.

27 Wicks JR, Oldridge NB, Cameron BJ, Jones NL. Arm cranking and wheelchair ergometry in elite spinal cord injured athletes. Med Sci Sports Ex 1983;15:224-31.

28 Rowell LB, Kraning KK, Evans TO, Kennedy JW, Blackmon JR, Kusumi $F$. Splanchnic removal of lactate and pyruvate during prolonged exercise in man. $\mathcal{F} A p p l$
Physiol 1966;21:1773-83. Pimental NA, Sawka MN, Billings DS, Trad LA. Physiological responses to prolonged upper body exercise. Med Ological responses to prolonged
Sci Sports Exerc $1984 ; 16: 360-5$.

30 Rowell LB. Human cardiovascular adjustments to exercise and thermal stress. Physiol Rev 1974;54:75-159.

31 Rowell LB. Circulation. Med Sci Sports Exerc 1969;1:15-22.

32 Glaser RM. Exercise and locomotion for the spinal cord injured. Exerc Sports Sci Rev 1985;13:263-303. 